\title{
O Ensino-Aprendizagem de Língua Inglesa em Escolas Públicas: O Real e o Ideal
}

\author{
Ricardo Santos David ${ }^{1}$ \\ ${ }^{1}$ Mestre em Educação: Formação de Professores, pela UNIATLANTICO - Espanha. - ricardosdavid@hotmail.com \\ Pós-graduado em Docência do Ensino Superior. Professor de língua inglesa para a educação infantil, ensino fun- \\ damental I e II.
}

Recebido em 10 de outubro de 2016; Aceito em 14 de dezembro de 2016.

\begin{abstract}
Resumo
Percebe-se que o ensino do inglês em escolas públicas, atualmente esta carregado de críticas e questionamentos. Diante disso, a proposta deste artigo é de analisar os fatores que fazem com que esse idioma seja tão relevante no mundo moderno, e porque perante tal asseveração prevalece um ambiente de dificuldades e barreiras tanto da parte do professor como do aluno nas escolas públicas brasileiras. A partir do referencial traçado é possível dizer que as questões que impedem a idealização do inglês nas escolas públicas advêm das dificuldades dos professores em transmitir seus conhecimentos e dos alunos pela falta de conhecimento prévio fonológico e de problemas inerentes ao ensino público, tão bem caracterizado no Brasil.
\end{abstract}

Palavras-chave: Ensino-aprendizagem; Inglês; Escolas Públicas.

\begin{abstract}
One perceives that the education of the English in public, this loaded of currently critical schools and questionings. Ahead of this, the proposal of this article is to analyze the factors that make with that this language is so excellent in the modern world, and because before such increase it in such a way takes advantage an environment of difficulties and barriers of the part of the teacher as of the pupil in the brazilian public schools. From the traced referencial it is possible to say that the questions that hinder the idealize English it in the public schools happen of the difficulties of the professors in transmitting its knowledge and of the pupils of the lack of phonologic previous knowledge and of inherent problems to so well characterized public education in Brazil.
\end{abstract}

Keywords: Teach-learning; English; Public schools. 


\section{INTRODUÇÃO}

Observa-se que o ensino do inglês constitui um fator importante para que qualquer pessoa inserida no meio social possa ter acesso ao mundo tecnológico e cultural. Portanto, tratar do tema sobre o processo de ensino e aprendizagem da língua inglesa em escolas públicas remete em primeiro instante no pensar sobre o que tem sido feito estrategicamente para que os alunos dessas instituições de ensino se interessem por outro idioma.

O ponto chave é que as pessoas possam ampliar a comunicação em um tempo de globalização e interação social constante e imediata.

Nesse sentido, o processo de ensino do inglês passa a ser visto como meio de aumentar as perspectivas culturais e profissionais de um cidadão. É por meio desse fato que as teorias se concentram em proporcionar aos alunos uma competência comunicativa que lhes permita desenvolver-se no ambiente: social, cultural e laboral. Tudo isso implica em noções e funções linguísticas, no uso apropriado das expressões, nas diversas situações comunicativas e de interlocutores, ou seja, a teoria atual de ensino e aprendizagem do inglês parece caminhar para um enfoque comunicativo.

Com isso, o papel do docente exerce uma função singular para que o alcance deste tipo de aprendizagem. Teóricos dissertam que o papel desempenhado pelos professores de línguas nas salas de aulas com certeza é relevante para a eficácia e eficiência da aprendizagem, podendo modificar o interesse do aluno. Como por exemplo, Siqueira (2005) explica que os professores de língua inglesa são detectores de um saber expressivo para a expansão de um idioma determinante para o desenvolvimento das sociedades atuais. Para tanto, um responsável para a consolidação do domínio inglês como língua mundial.

Diante disso, o objeto central deste trabalho se concentra em descrever e analisar como tem sido a relação de ensino-aprendizagem da língua inglesa entre professores e alunos no contexto das escolas públicas. Para tanto, se utiliza de uma pesquisa bibliográfica para situar o assunto e construir meios para análise do tema.

\section{O ENSINO DA LÍNGUA INGLESA}

Para Siqueira (2005) é público e notório que o inglês é o idioma principal da sociedade contemporânea. Como chama o autor, "[...] o latim dos tempos modernos". Portanto, não é um fenômeno que vem passando despercebido, pelo contrário, é possível ver que esta língua que atingiu um patamar que serve de pauta para diversos fins sociais, políticos, econômicos e institucionais.

Atualmente, o inglês é a língua nativa de mais de meio bilhão de pessoas oriundas tanto do centro quanto da periferia do globo. É a língua mais falada do mundo por não-nativos e, provavelmente, o único idioma que possui mais falantes não-nativos que nativos. São três falantes não-nativos para cada falante nativo (SIQUEIRA, 2005, p.14).

Observa-se que a pluralidade de situações em que um se depara com os discursos construídos em inglês em diversos meios de comunicação como a televisão, internet, livros, propagandas faz com ressalte a importância de seu ensino. Para Lopes (2003) a língua inglesa é atualmente responsável pela grande parte das informações disseminadas acerca dos fatos que acontecem em todo o planeta.

E corrobora Rajagopalan (2005) que o significado do ensino inglês se traslada à importância que dão os pais em promover em seus filhos o conhecimento dessa língua estrangeira, colocando-a não somente 
como uma segunda língua, mas, sobretudo como um determinante para o crescimento pessoal e profissional de seus filhos.

Utilizando-se um pouco do aporte da teoria da linguagem para solidificar a importância do ensino da língua inglesa, pode-se citar Daniels (2001, p.12), que vê a linguagem como o "mais poderoso e penetrante dos dispositivos semióticos - funciona como uma ferramenta psicológica na construção da consciência individual". Observa-se que o autor apresenta uma percepção de aprendizagem da língua como uma produção de sentidos, na qual o ser humano cria e se recria continuamente.

E ainda, como descrevem Spink e Medrado (2004, p.48), a linguagem em sua expressão polissêmica permite às "[...] pessoas transitar por inúmeros contextos e vivenciar variadas situações". Isso ressalva o objetivo maior que é a compreensão que se reproduz no cenário contemporâneo com a aprendizagem do inglês.

Para tanto, percebe-se que o ensino da língua dever ter como ponto inicial para aprendizagem um fator importante: um constante relacionamento com o cotidiano, com o que acontece na rotina diária das pessoas, de maneira que permita ao indivíduo satisfazer suas necessidades pessoais.

No entanto, quando o tema passa para o dia-a-dia, observam-se certos entraves no cenário brasileiro, advindos de uma época em que a língua inglesa era considerada como apolítica e agente do imperialismo americano, e quando o ensino se baseava na prática de diálogos descontextualizados e memorizados sem significância social.

Abordam Pagliarini Cox e Assis-Peterson (2001, p.17) que foi somente a partir dos anos de 1970, frente à noção de competência comunicativa, que o ensino do inglês passou a ser percebido como uma habilidade funcional, na qual não somente se deveriam incluir regras gramaticais, como também "[...] uma competência pragmática, exigida para a interpretação, expressão e negociação de sentido no contexto imediato da situação de fala. O foco das atividades da sala de aula se desloca da forma (correção gramatical) para o sentido (fluência comunicativa)".

Porém, esse enfoque comunicativo entra também em declínio, quando os teóricos começam a questionar o caráter apaziguador e harmônico do ensino de inglês, como um meio de conhecer outra cultura e fazer amigos. Frente a um mundo globalizado, capitalista, democrático, inovador e moderno não se podem conceber o idioma apenas como uma mera percepção passiva. Descrevem Pagliarini Cox e Assis-Peterson (2001, p. 4) que pensadores como Pennycook aludem ao ensino do inglês como um instrumento da comunicação global, onde:

Quem ensina inglês não pode deixar de se colocar criticamente em relação ao discurso dominante que representa a internacionalização do inglês como um bem, um passaporte para o primeiro mundo. Quem ensina inglês não pode deixar de considerar as relações de seu trabalho com a expansão da língua, avaliando criticamente as implicações de sua prática na produção e reprodução das desigualdades sociais. Quem ensina inglês não pode deixar de se perguntar se está colaborando para perpetuar a dominação de uns sobre os outros.

Tomando como foco de análise o ensino do inglês no mundo moderno, comenta Rocha (2006) que em muitos países da União Européia, da Ásia e da África o ensino se desenvolve por um período relativamente longo, durante o qual os objetivos estão explicitados e os referenciais teóricos bem constituídos. Ao contrário, na America do Sul, a expansão do ensino do inglês se expressa de maneira bastante aleatória. E em rela- 
ção ao cenário educacional brasileiro, a aprendizagem do idioma se apresenta em uma teorização incipiente.

Descreve Oliveira (2003) que se reconhece na literatura uma ineficiência em relação ao ensino em grande parte das escolas do setor público.

Diante dos fatos apresentados, é possível ver também que os resultados insatisfatórios quanto ao ensino de línguas estrangeiras, como neste caso o inglês, faz insurgir por parte de alguns pesquisadores o interesse de compreender o que influencia na prática do professor e no desempenho do aluno, dentro da relação ensino-aprendizagem.

\section{O PROFESSOR DE INGLÊS}

No cotidiano profissional de hoje é comum a sensação de desilusão com as "soluções dos teóricos" ante o pouco progresso visível da qualidade do ensino de línguas frente aos olhos e expectativas crescentes de alunos e autoridades.

Observa que, para muitos professores de inglês, não existe a preocupação pela formação social do aluno. Nem sempre as discussões giram em torno das atitudes dos alunos no convívio social. Parece que a missão de educar se delega às disciplinas básicas no ensino regular e às famílias. Isso ocorre principalmente em escolas públicas, onde a relação ensino-aprendizagem do inglês é observada com preconceito, onde os professores em sua maioria consideram que os alunos são incapazes de aprender outro idioma, uma vez que possuem dificuldade de aprender o próprio português.

Agrega Piccoli (2006, p.2):

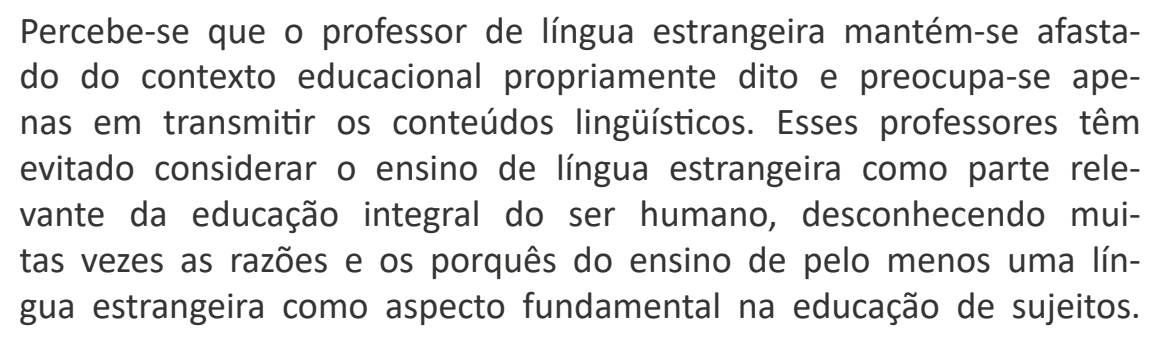

Vieira-Abrahão (1996) observa que a sala de aula, durante o ensino de inglês, muitas vezes se transforma em um campo repleto de "conflitos e incertezas" por parte dos professores frente ao próprio trabalho.

Esses conflitos e incertezas, quando relacionadas ao fato do professor não ser nativo da língua inglesa, se dão pela falta de domínio suficiente do conteúdo. Segundo Kelly (2000), muitos professores relatam que a falta de tempo para sua própria aprendizagem e domínio total do idiomam dificulta muito a relação de ensino na sala de aula. Há aqueles que possuem dificuldades na pronúncia e ainda citam a falta de apoio pedagógico por parte da instituição. Claro que para um brasileiro a diferença entre os dois idiomas é algo que realmente complica.

No entanto, esses problemas não podem se converter em barreiras que impeçam a reflexão sobre a prática didático-pedagógica do objeto em questão. Buscando a ajuda de Freire e Shor (1993, p.48) pode-se dizer que o professor, independente da disciplina que Ihe seja conferido, deve ser acima de tudo um educador libertador,

[...] atento para o fato de que a transformação não é só uma questão de métodos e técnicas. Se a educação libertadora fosse somente uma questão de métodos, então o problema seria algu- 
mas metodologias tradicionais por outras mais modernas, mas não é esse o problema. A questão é o estabelecimento de uma relação diferente com o conhecimento e com a sociedade. [...].

No contexto da prática pedagógica do inglês, ilustram Deo e Duarte (2004) que o professor deve estar consciente para a necessidade de incluir em sua rotina diária alguns momentos de reflexão e questionamento sobre as ações que circulam no cenário do idioma. O professor não deve ser um mero transmissor de conteúdo, mas sim um profissional que envolve, expressa e constrói apreciações.

Talvez fosse isso que pensaria Vygotsky (1998) frente as dificuldades do professores: que eles deveriam buscar novos meios para estimular o trabalho colaborativo, potencializando o desenvolvimento cognitivo dos alunos.

Para tanto, o ideal para o ensino seria a organização do ambiente que é a base para que o aprendiz se sinta estimulado à aprendizagem. $O$ inglês, como um rico idioma que transita em vários mundos, requer do professor um trabalho de mediador, mediante o qual possa levar o aluno ao mundo da descoberta, da motivação, do querer entender e buscar, onde o mesmo possa ser a peça-chave de seu desenvolvimento.

Considera Piccoli (2006, p.5) que o ensino do inglês implica por parte do professor um compromisso de oportunidades para si e para seus alunos, isto é, de um acordo para a construção de análises e síntese visando um viver e agir em sociedade, "[...] trabalhando partes e vislumbrando o todo complexo".

Almeida Filho (1998), um grande investigador da Lingüística Aplicada, considera que o ensino comunicativo é aquele que busca organizar experiências de aprender por meio de atividades de real interesse e/ou necessidade do aluno, com o escopo de que este seja capaz de usar a língua-alvo para realizar atos verdadeiros na interação com outros sujeitos que também fazem uso dessa língua.

Seguindo nessa trajetória de pensamento, Piccoli $(2006$, p.5) disserta:

É necessário que o professor tenha em mente que permitir a si e a seus alunos a (des) construção, reconstrução e reformulação de conteúdos é passar de respondedor a questionador, é manter-se reflexivo, questionando sempre o porquê e o para quê, pois o saber construído sobre a relevância e aplicabilidade dos conteúdos e na confiança e poder que o educador outorga aos educandos constitui-se também objeto de transformação social.

Com isso, é possível dizer que na prática da língua inglesa, muitas vezes se faz necessário que o professor deixe sua "mesa" para ir ao encontro de seus alunos, onde o "saber" implica em aprender a compartir representações e estímulos.

Como diria Freire (2003, p.47) "ensinar não é transferir conhecimento, mas criar as possibilidades para sua própria produção ou sua construção".

\section{O DESEMPENHO DO ALUNO}

Não se pode deixar de relatar que o ensino público é marcado pela desigualdade social, econômica e cultural. Problemas advindos da utilização de metodologias inadequadas ao contexto, desvalorização e despreparo dos educadores, tecnologias obsoletas na formação do aluno, falta de investimentos e políticas públicas mal dirigidas.

Descreve Barcelos (2006) que, em geral, a experiência de aprendizagem em escolas públicas se carac- 
teriza como ruim e sem motivação. Esse cenário é composto por problemas pedagógicos, falta de interesse dos alunos, a não prática da língua e a falta de competência de grande parte dos professores.

Kelly (2000) narra que a aprendizagem do inglês decorre muitas vezes da falta de interesse do aluno, quando se nota a falta de integração com a pronúncia, com a gramática e vocabulário. É válido ressaltar também que a falta de tempo dificulta o entrosamento do aluno com o idioma.

Além disso, por ser um idioma totalmente distinto da língua materna, esse fato faz com que o aluno se sinta encabulado para se expressar, desta maneira a falta de contato prévio em relação aos aspectos fonológicos prejudicam ainda mais a relação ensino-aprendizagem.

Ilustra Barcelos (2006, p.161) que as desculpas apresentadas pelos alunos pela dificuldade de aprender inglês muitas vezes se resumem:

[...] à repetição de um ensino que geralmente parece ser bastante voltado para aspectos gramaticais e o mais lembrado é o verbo to be. O outro aspecto mencionado no excerto diz respeito a um discurso presente em nossa sociedade - o da falta de competência dos professores de escola pública.

Em um trabalho sobre as representações sociais dos alunos de escola pública, em relação à aprendizagem da língua inglesa em Maceió (AL), Lima e Sales (2007) citam que a realidade se compõe de alunos que não possuem recursos didáticos adequados ao ensino da língua, além de não terem estímulos, e ainda se representam como uma categoria com significativo déficit cultural.

Considerando, ainda, que para muitos alunos somente é possível aprender inglês em cursos particulares, sendo improvável, portanto adquirir o conhecimento da língua estrangeira em uma escola pública. As locuções que surgem nesse meio sempre se traduzem em comentários dos professores que os alunos não conseguem aprender inglês.

Eles não sabem de coisa alguma, quer dizer... Eles não têm esse contato com a língua. É difícil. Imagine, eles não têm nem como, não têm recurso, não tem como se desenvolver, como crescer na aprendizagem da língua, não tem como (LIMA; SALES, 2007, p.7).

Agregam-se ainda os problemas familiares e o baixo nível socioeconômico, que fazem com que os alunos apresentem cada vez menos interesse pela aprendizagem da língua estrangeira.

Diante desses dilemas que emergem no cenário da aprendizagem do inglês em escolas públicas, Barcelos (2006) pergunta o que pode ser feito por parte dos professores, sem levar em conta os problemas econômicos, sociais e culturais que permeiam o mundo do ensino público.

Para a autora, o sonhado seria o esforço consciente do professor de língua estrangeira em se comprometer com uma educação pública de qualidade. Isso requer o conhecimento sobre as crenças e experiências dos alunos, como também a troca de ideias e a meditação sobre as experiências vividas em meio de uma aprendizagem reflexiva. É preciso "[...] ajudar os alunos a refletir sobre sua própria aprendizagem e sobre suas crenças e experiência" (BARCELOS, 2006, p.146).

Para Pacheco (1994) isso seria a emancipação de todo e qualquer conhecimento que se constitui em uma aprendizagem significativa dos alunos. O aluno é construtor da aprendizagem e conseqüentemente busca a descoberta pessoal e a valorização dos saberes adquiridos.

Acrescenta Grundy (1991) que interesse emancipador implica em atitudes do professor e dos alunos 
em modificar as condições onde se produz a aprendizagem e que limita a liberdade, tanto em procedimentos como em conteúdos.

\section{CONCLUSÃO}

Foi possível perceber neste pequeno ensaio sobre a relação ensino-aprendizagem do inglês em escolas públicas, que para muitos esse não parece ser o lugar ideal para se aprender uma língua estrangeira.

Observa-se, segundo o referencial teórico, que ocorre uma imobilidade em relação ao ensino da língua inglesa, advindo de problemas culturais, econômicos e sociais, além das próprias dificuldades inerentes ao professor em disseminar o conhecimento de um idioma que muitas vezes nem faz parte de seu próprio cenário cultural e social.

Pode-se dizer que os problemas que norteiam o ensino da língua inglesa no cenário brasileiro, em muitos casos ultrapassam o âmbito da escola pública, apesar do discurso da relevância do inglês para o crescimento profissional e social dos indivíduos. Por mais imaginária que seja a construção da importância do inglês na sociedade contemporânea, a realidade faz com que se depare com um ensino carregado de conflitos, incertezas.

Buscando nos estudos de Freire (2003) fundamentos para terminar esta análise, observa-se que o homem é quem constrói a sua história, compartilhada com outras e reconstruídas em outras. À luz desse pensamento, observa-se que dentro do processo de ensino-aprendizagem do inglês somente será possível construir um enredo quando o cotidiano do professor e do aluno conseguir se permear de experiências, expressões e sentidos.

\section{REFERÊNCIAS}

ALMEIDA FILHO, José Carlos de. Dimensões comunicativas no ensino de línguas. Campinas/SP: Pontes, 1998.

BARCELOS, Ana Maria Ferreira. Narrativas, crenças e experiências de aprender inglês. Linguagem \& Ensino, v.9, n.2, p.145-175, jul./dez. 2006.

DANIELS, Harry. Vygostsky e a pedagogia. São Paulo: Loyola, 2001.

DEO, Aldisnéia Santos Rossi De; DUARTE, Luiza Maria. Análise de livro didático: as diversas abordagens e métodos aplicados ao ensino de língua estrangeira. Revista Eletrônica Unibero de Produção Científica, set. 2004. Disponível em:< http://www.unibero.edu.br/ >. Acesso em:

FREIRE, Paulo. Pedagogia da autonomia: saberes necessários à prática educativa. São Paulo: Paz e Terra, 2003.

; SHOR, Iria. Medo e ousadia. Rio de Janeiro: Paz e Terra, 1993.

GRUNDY, Shirley. Producto o praxis del curriculum. Madrid: Morata, 1991.

KELLY, Gerald. How to teach pronunciation. Essex: Pearson Education Limited, 2000.

LIMA, Francisca de Fátima de; SALES, Luís Carlos. Professores de inglês do ensino básico: representações sociais do aluno de escola pública. Anais... 18 EPENN - Encontro de Pesquisa Educacional do Norte e Nordeste, 2 de julho de 2007, Alagoas, 2007.

MOITA LOPES, Luiz P. Oficina de linguística aplicada: a natureza social e educacional dos processos de ensino/aprendizagem de línguas. São Paulo: Mercado de Letras, 1996.

OLIVEIRA, Enio de. Políticas de ensino de línguas estrangeiras em escolas públicas do Estado de São Paulo. Dissertação (Mestrado em Linguística Aplicada) - IEL/Unicamp, Campinas/SP, 2003.

PACHECO, Jose Augusto B. Área escola: projecto educativo, curricular e didáctico. Revista Portuguesa de Educação, v.7, 
n. 1-2, p. 49-80, 1994.

PAGLIARINI COX, Maria Inês; ASSIS-PETERSON, Ana Antônia de. O professor de inglês Entre a alienação e a emancipação. Linguagem \& Ensino, v. 4, n. 1, p.11-36, 2001.

PICCOLI, Maria Cecília. O educador em língua dominante e o desenvolvimento sustentável. Revista X, v.1, p.1-16, 2006.

RAJAGOPALAN, Kanavillil. The ambivalent role of English in Brazilian politics. World Englishes, v. 22. n. 2, p. 91-101, 2003.

ROCHA, Cláudia Hilsdorf. Provisões para Ensinar LE no Ensino Fundamental de 1a a 4a Séries: dos Parâmetros Oficiais e Objetivos dos Agentes. 2006. Dissertação (Mestrado em Lingüística Aplicada) - Universidade Estadual de Campinas, Campinas/SP, 2006.

SIQUEIRA, Sávio. O desenvolvimento da consciência cultural crítica como forma de combate à suposta alienação do professor brasileiro de inglês. Revista Inventário, n.4, jul. 2005.

SPINK, Mary Jane; MEDRADO, Benedito. Produção de sentidos no cotidiano: uma abordagem teórico-metodológica para análise das práticas discursivas. In: SPINK, Mary Jane (org.). Práticas discursivas e produção de sentidos no cotidiano. São Paulo: Cortez, 2004.

VIEIRA-ABRAHÃO, Maria Helena. Conflitos e incertezas do professor de língua estrangeira na renovação de sua prática de sala de aula. Tese (Doutorado) - IEL, Unicamp, Campinas/SP, 1996.

VYGOTSKY, Lev. S. A formação social da mente. São Paulo: Martins Fontes, 1998. 